\title{
PETROCHEMISTRY AND CHEMICAL FEATURES OF LUNAR GLASSY SPHERULES
}

\author{
R. TRIGILA \\ University of Rome, Rome, Italy
}

\begin{abstract}
The major elements of glassy spherules from samples 12001.73, 12057.60 and 12070.37 of lunar fines have been determined by electron probe analysis. The bulk chemistry of these spherules (which are between $200 \mu \mathrm{m}$ and $62 \mu \mathrm{m}$ in size) falls in most cases within the range of gabbro-peridotite and gabbro-anorthosite.

In individual spherules, the grade of chemical homogeneity is highly variable and can be related to the possible presence of small inclusions or sometimes to slight concentration gradients evident near the peripheries of the particles. These features, together with the presence of vesicles of different size in association with strong alkali enrichment along the boundaries of such cavities can account for relationships between the chemistry of the particles and their genetic history.
\end{abstract}

\section{Introduction}

The origin and composition of the glasses from samples of the fines collected in the Apollo missions have already been described by several investigators.

Comprehensive studies on the morphological and chemical characteristics of these materials have been published by Agrell et al. (1971), Chao et al. (1970) and McKay et al. (1970). Among others, Isard (1971) and Carusi et al. (1972) made models to explain on a theoretical basis the formation of glassy particles by impact of meteoritic bodies on the lunar surface.

It is generally accepted that the great majority of lunar glasses are impactoclastic in origin rather than representative of liquids of magmatic origin. Basic considerations on the relationships between abundance, size, shape and chemical composition of the glasses found in the lunar regolith seem to support this view. In particular, the widespread occurrence of shock structures, of glass corresponding in composition to single mineral phases and of a fine powdery coating on the particles investigated can be well explained by impact events. The occasional presence of flow structures and of iron droplets inside the glasses are further confirmation of very rapid melting and subsequent quenching over a range of physical parameters far from those characteristic of magmatic processes. Researches on pit-craters have led to the conclusion that the chemistry of the glassy particles is much more affected by the size of the impacting body in relation to the grain size of the target rock than by a selective distribution of major elements as a consequence of the impact event.

On the other hand it is also possible that some homogeneous glasses have originated through volcanic activity. Unfortunately no investigations have as yet been possible on lunar glass spheres of undoubted volcanic origin. Some indications may however be obtained from a comparative study of terrestrial glasses and lavas from the same eruption. Such work is now in progress on material collected during the latest eruption of Etna and the chemistry is in some ways similar to that of the lunar rocks. 
TABLE

Electron Probe Analyses

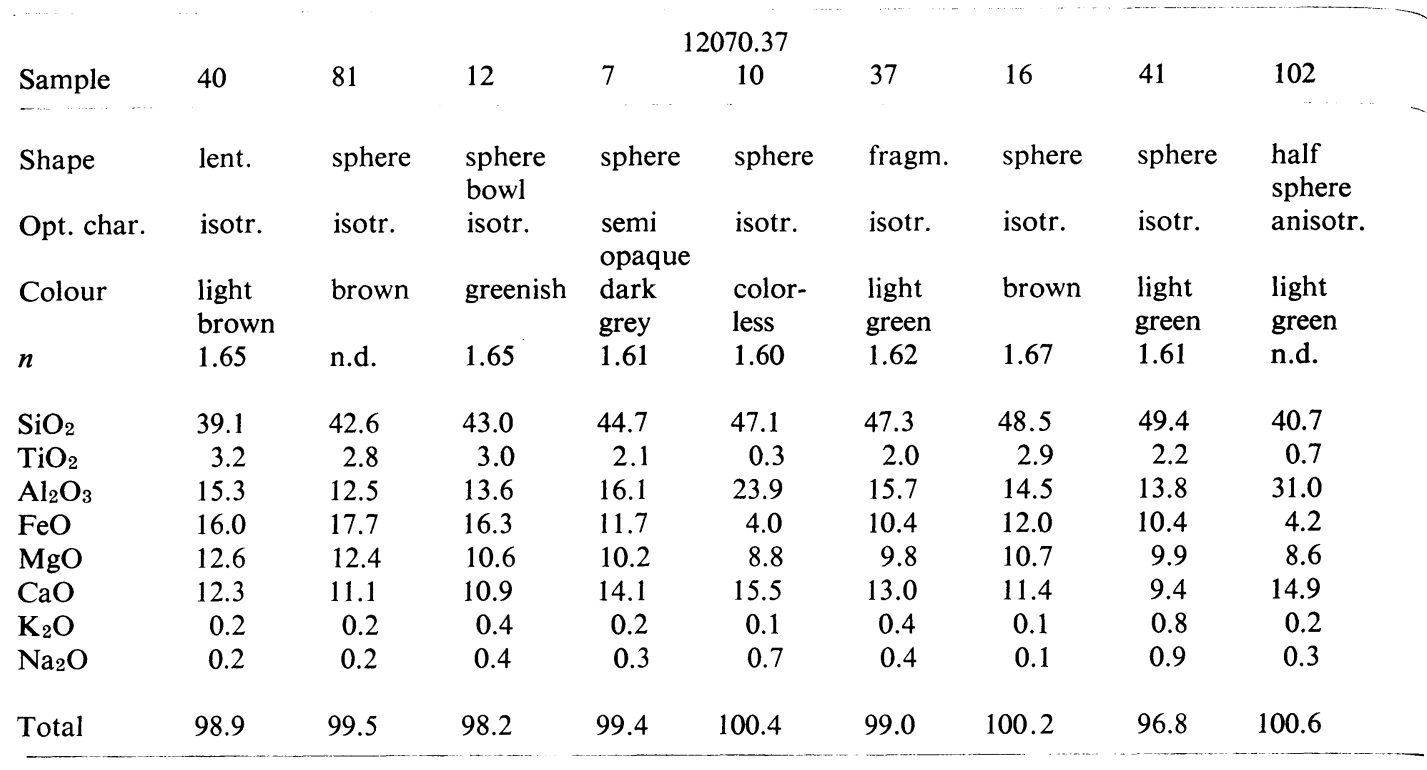

\section{Petrochemical Considerations}

The major elements of 19 glassy particles extracted from samples 12001.73, 12057.60, 12070.37 of lunar fines have been determined by electron microprobe to supply data on bulk compositions and the relationships between such compositions and those of some elements of unique distribution possibly as a consequence of the glass formation processes.

Table I gives values for the oxides of $\mathrm{Si}, \mathrm{Ti}, \mathrm{Al}, \mathrm{Fe}, \mathrm{Mg}, \mathrm{Ca}, \mathrm{K}$ and $\mathrm{Na}$, together with some physical characteristics. Silica ranges almost regularly from 39 to $49 \%$ with the exception of the ellipsoid 145 in which it is $54.2 \%$. Regular variations can be observed for $\mathrm{MgO}(8.5-15.2 \%)$, for $\mathrm{CaO}(9-15.5 \%)$ and to a minor extent for the alkalies, which normally range from 0.1 to $0.5 \%$, but in sphere $41 \mathrm{~K}_{2} \mathrm{O}$ is $0.8 \%$ and $\mathrm{Na}_{2} \mathrm{O}$ is $0.9 \%$. Most of the values for alumina lie between 8.6 and $16.1 \%$, the few remaining, between 20.7 and $31.0 \%$. This kind of distribution can be observed for $\mathrm{FeO}$ and $\mathrm{TiO}_{2}$, their values being bimodal: a major group for the high values and a minor one for the low values. In Figure 1 where $\mathrm{FeO}$ has been plotted against $\mathrm{Al}_{2} \mathrm{O}_{3}$ a negative correlation is clearly shown.

Niggli basis bonds and standard katanorms are plotted in Tables II and III respectively. Most of the glasses are characterized by the predominance of the normative paragenesis feldspar-pyroxene-olivine and lie within the field of gabbro composition. A few glasses $(102,10,133)$ have a very high content of normative plagioclase and can be equated with gabbro-anorthosite to anorthosite types while others $(40,81$, 
I of Apollo 12 glasses

\begin{tabular}{|c|c|c|c|c|c|c|c|c|c|}
\hline \multirow{2}{*}{$\ldots$} & \multicolumn{3}{|c|}{12001.73} & \multirow[b]{2}{*}{172} & \multicolumn{5}{|c|}{12057.60} \\
\hline & 105 & 104 & 103 & & 138 & 133 & 142 & 144 & 145 \\
\hline \multirow{5}{*}{$\begin{array}{l}\text { tear } \\
\text { drop } \\
\text { semi } \\
\text { opaque } \\
\text { dark } \\
\text { brown } \\
\text { n.d. }\end{array}$} & sphere & ellip. & sphere & tear & half & tear & ellip. & ellip. & half \\
\hline & & & & drop & ell. & drop & & & ell. \\
\hline & semi & isotr. & isotr. & isotr. & isotr. & anisotr. & isotr. & opaque & isotr. \\
\hline & brown & brownish & $\begin{array}{l}\text { light } \\
\text { brown }\end{array}$ & brown & urown & $\begin{array}{l}\text { dark } \\
\text { grey }\end{array}$ & $\begin{array}{l}\text { reddish } \\
\text { oran. }\end{array}$ & grey & brown \\
\hline & n.d. & 1.67 & 1.67 & n.d. & n.d. & n.d. & n.d. & n.d. & n.d. \\
\hline 40.9 & 40.9 & 41.1 & 42.4 & 44.0 & 44.9 & 47.4 & 47.8 & 49.4 & 54.2 \\
\hline 3.4 & 2.8 & 2.9 & 3.0 & 2.8 & 2.6 & 2.1 & 4.0 & 2.9 & 2.3 \\
\hline 12.0 & 14.0 & 15.4 & 12.2 & 12.8 & 10.5 & 20.7 & 8.6 & 11.2 & 13.0 \\
\hline 16.7 & 14.2 & 15.5 & 16.8 & 15.6 & 17.4 & 8.0 & 17.9 & 15.2 & 12.5 \\
\hline 11.1 & 15.2 & 12.9 & 12.0 & 11.9 & 10.9 & 8.5 & 11.3 & 10.3 & 8.8 \\
\hline 12.5 & 9.5 & 11.0 & 10.0 & 12.7 & 12.7 & 13.0 & 9.0 & 10.6 & 10.1 \\
\hline 0.5 & 0.2 & 0.2 & 0.2 & 0.3 & 0.1 & 0.2 & 0.2 & 0.4 & 0.4 \\
\hline 0.5 & 0.1 & 0.1 & 0.2 & 0.5 & 0.1 & 0.4 & 0.3 & 0.4 & 0.6 \\
\hline 97.6 & 97.0 & 99.1 & 97.0 & 100.6 & 99.2 & 100.3 & 99.1 & 100.4 & 101.9 \\
\hline
\end{tabular}

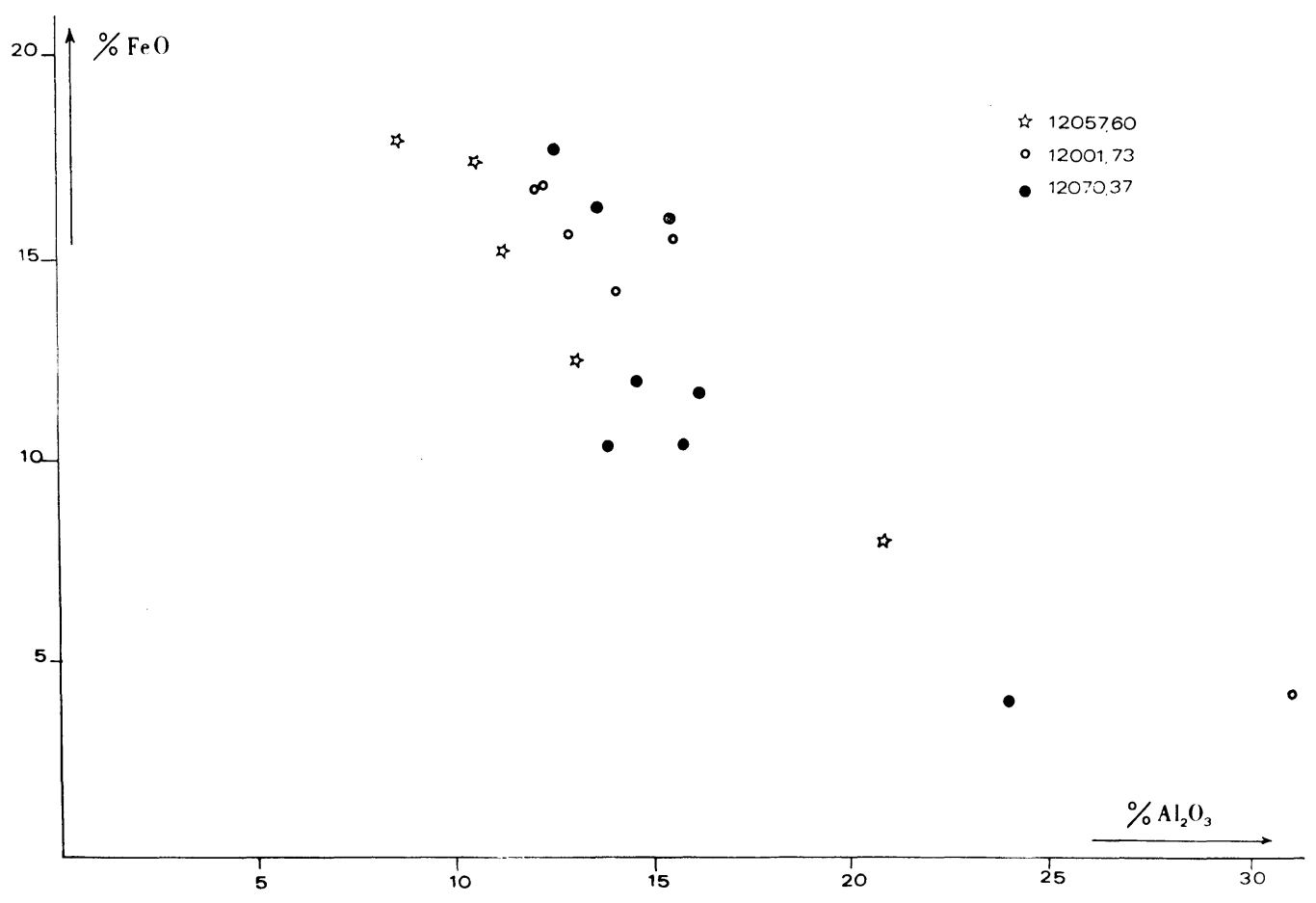

Fig. 1. Diagram showing the inverse correlation of $\mathrm{Al}_{2} \mathrm{O}_{3}$ with $\mathrm{FeO}$. Glasses analyses from different samples plot with the same distribution. 
年

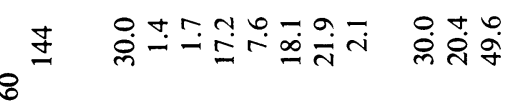

过 艺

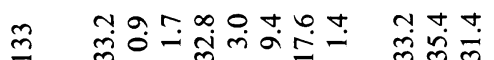

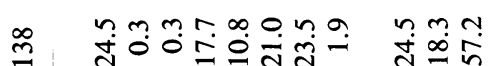

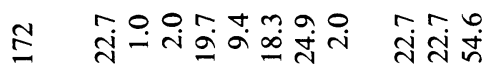

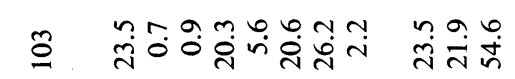

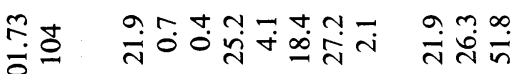

din hrtmono nTo

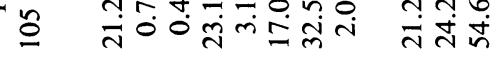

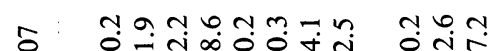

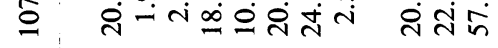

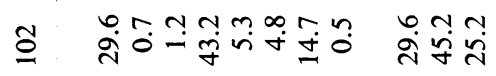

F

-

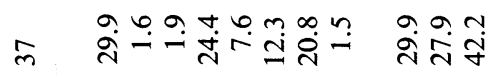

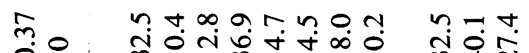

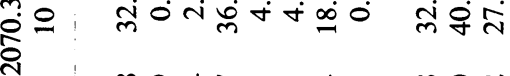

-

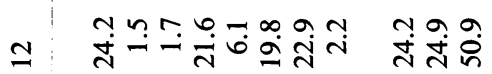

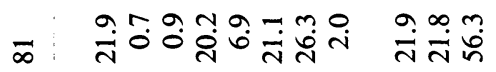

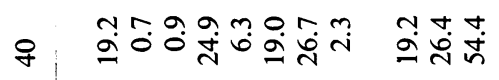

离

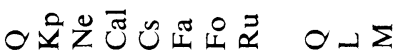




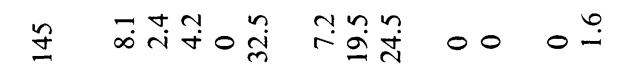

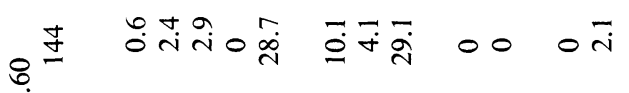

产先

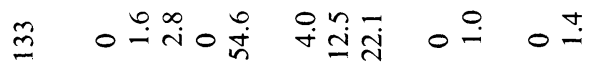

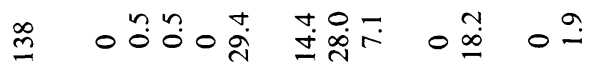

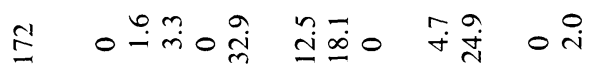

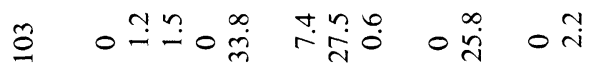

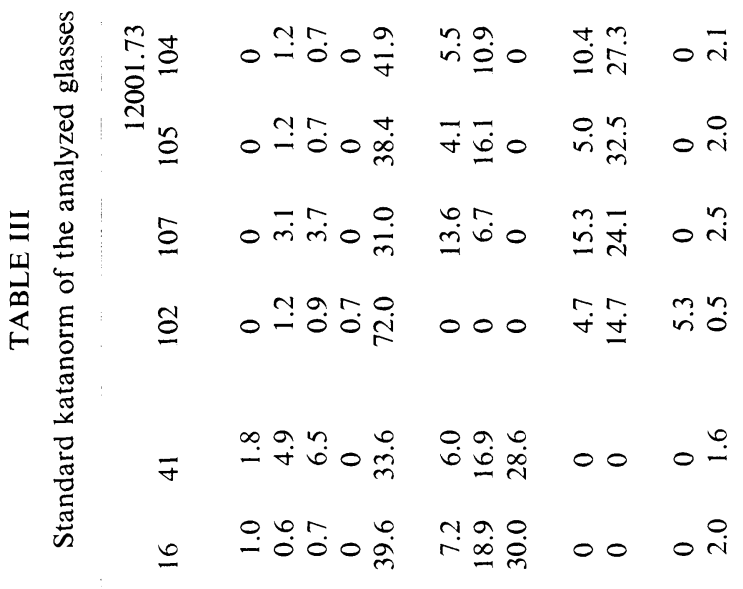

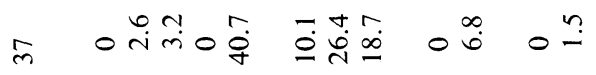

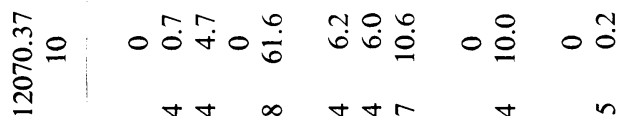

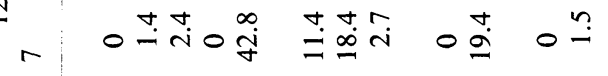

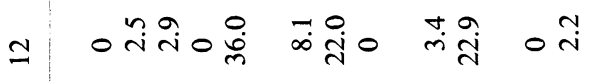

क

o

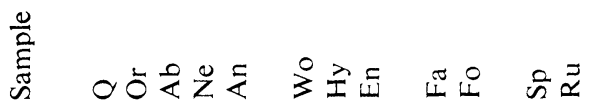


$107,105,104)$ show olivine predominating over pyroxene and a shift to gabbroperidotite composition.

A comprehensive picture of the bulk chemistry of the analysed glasses comes from the representation of the Niggli QLM triangle where $Q$ is the basis quartz and L and $M$ represent the leucocratic and melanocratic basis values respectively (Figure 2). If we now consider an impactoclastic origin for most of the particles which Mason and Melson (1970) reported as mainly produced by melting of various proportions of pyroxene, plagioclase and olivine or of preexisting glasses, one would expect to find some trend towards these mineral compositions. According to Chao et al. (1970) two different trends can be recognized in the Apollo glasses: a major one connecting the gabbro compositions with the anorthositic and a minor one in the direction of increasing or decreasing olivine. This situation may be recognized for the group of glasses analyzed here: almost all the points are distributed within the field PFR below the saturation line PF. The occurrence of the oversaturated composition in glass 145 could also be explained by a melting of a high silica parent rock.

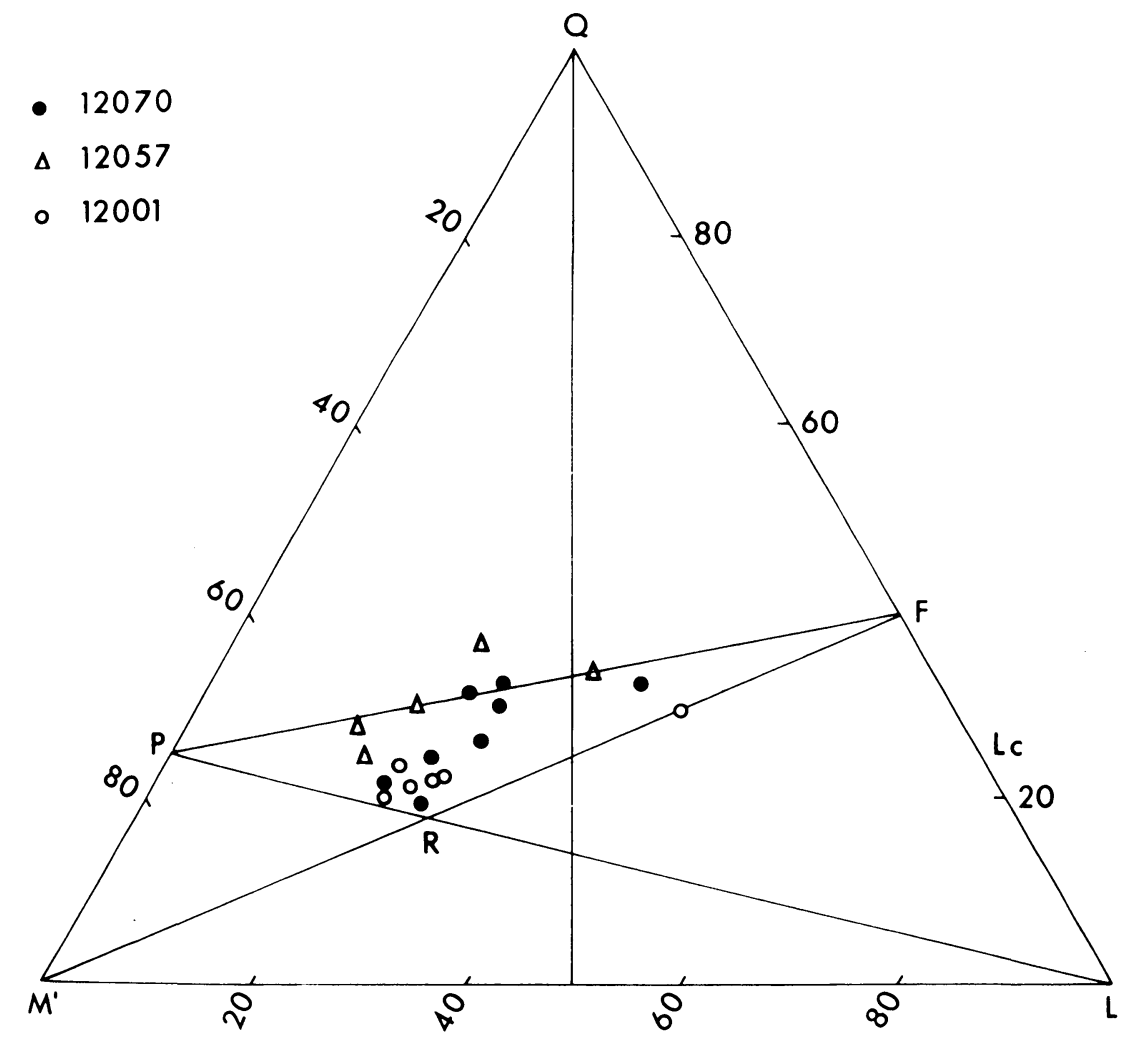

Fig. 2. The Q-L-M diagram. Almost all the glasses analyses plot in the field P-F-R which corresponds to the major paragenesis pyroxene-feldspar-olivine. The line $\mathrm{Q}-50 \% \mathrm{~L}$ divides the gabbro rich compositions from the anorthosite rich compositions. 


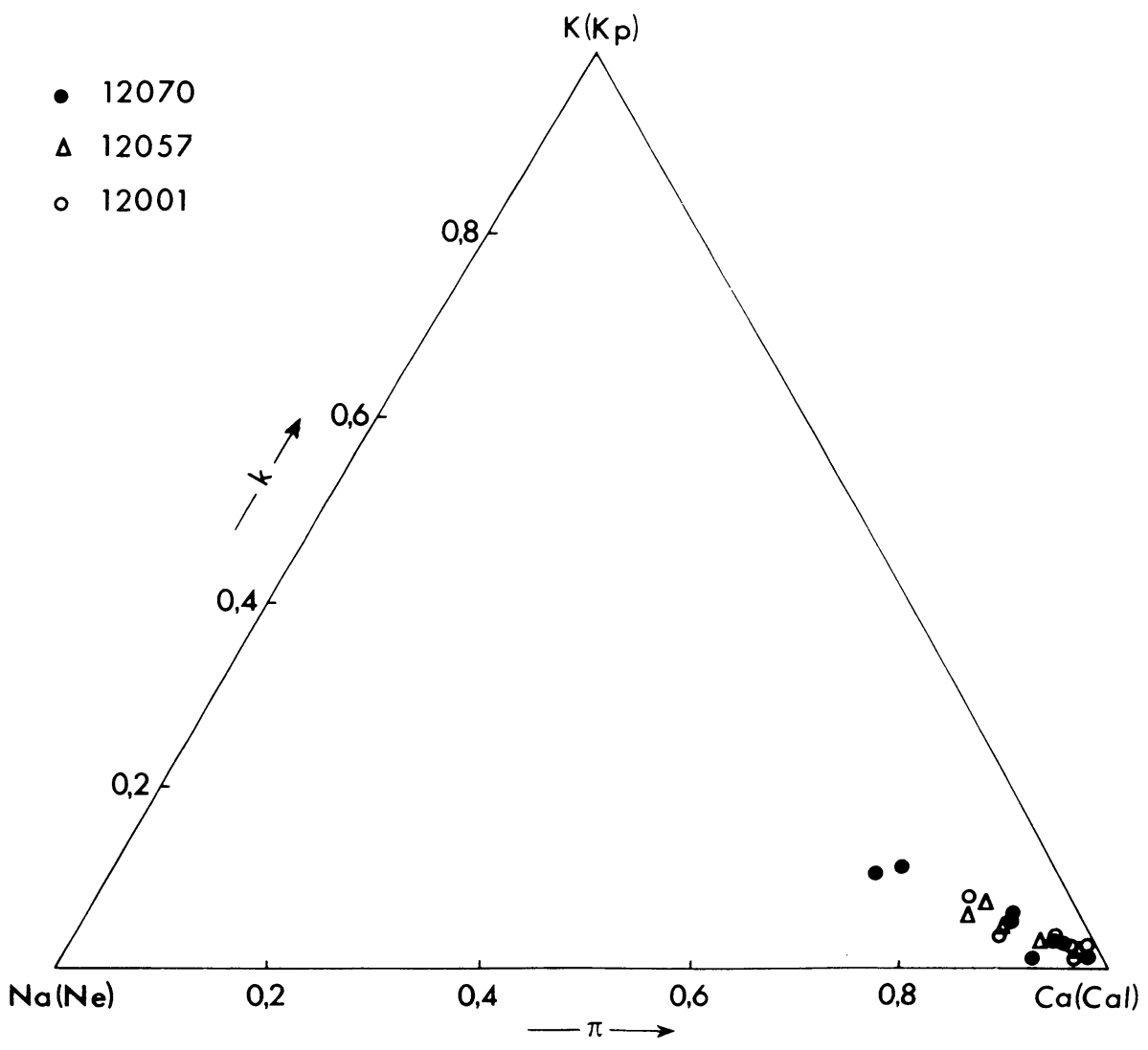

Fig. 3. The feldspar diagram shows the balance between normative orthoclase and albite along the line $0.4 \mathrm{k}$.

Figure 3 gives the composition of the normative feldspar. Most of the values are in the range $85-95 \%$ An, in good agreement with the feldspar compositions already observed for Apollo 12 rocks and lithic fragments. In several cases, some sort of balance can also be observed between the relative amounts of the $\mathrm{Na}$ and $\mathrm{K}$ normative feldspars. This does not seem to fit in with the general prevalence of normative albite over normative orthoclase in lunar rocks or lithic fragments (Keil et al., 1971). As depletion in alkalies has been inferred for a certain group of glasses as a consequence of their formative processes (Agrell et al., 1971) a differential volatilization of alkalies through the impact mechanism may account for the modification of the $\mathrm{K} / \mathrm{Na}$ ratio in the normative feldspars.

The relationships between $\mathrm{Mg}, \mathrm{Fe}$ and $\mathrm{Ca}$ in the mafic components is shown in Figure 4 where the Fo, Fa and Cs values of the Niggli basis bonds have been plotted. As already noticed by Chao et al. (1970), there is a balance of the $\mathrm{Mg}$ and Fe silicates for most of the glasses. 


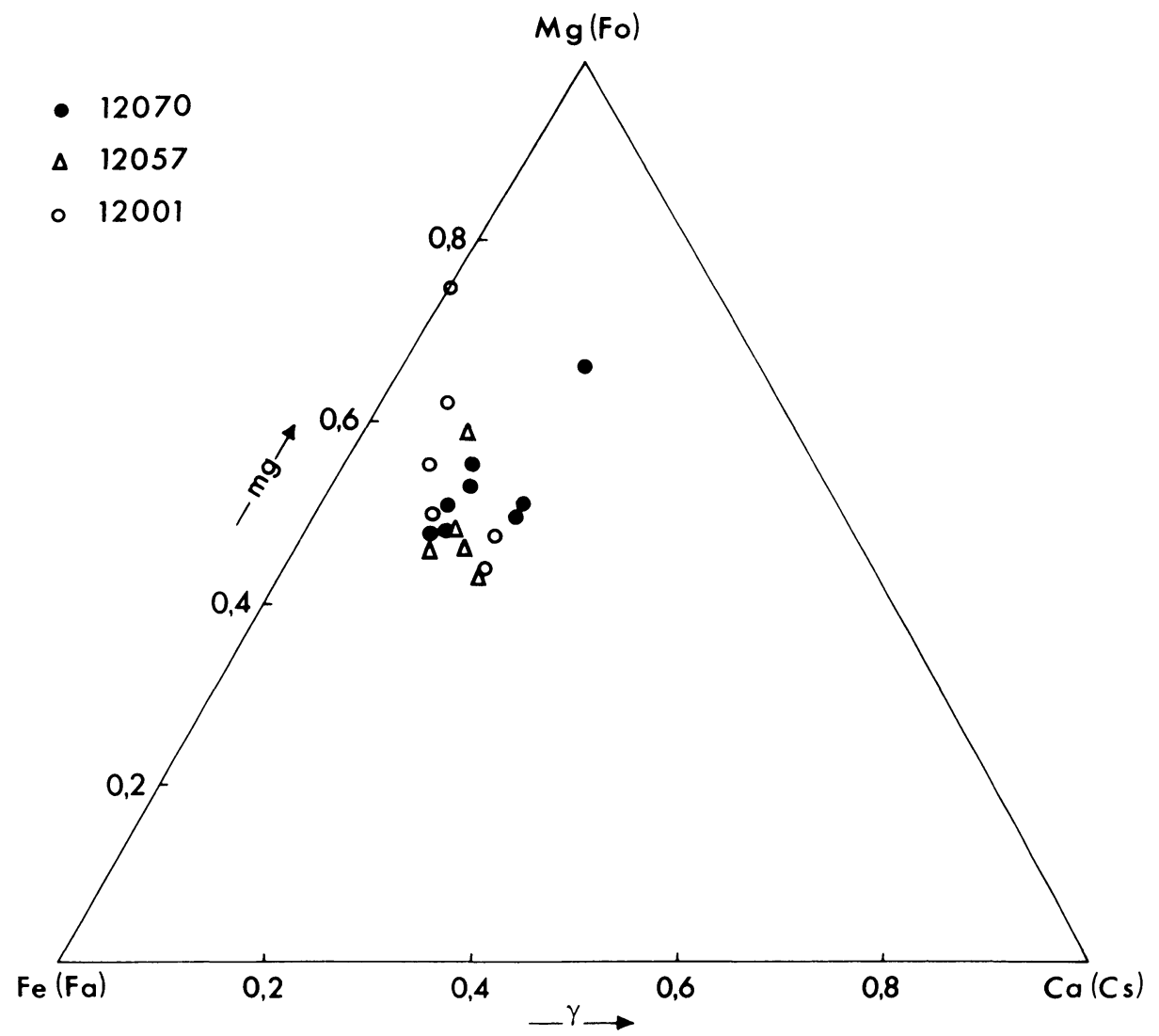

Fig. 4. The $\mathrm{Mg}$ - $\mathrm{Fe}-\mathrm{Ca}$ triangle illustrates the quantitative relationships of $\mathrm{Fe}, \mathrm{Mg}$, and $\mathrm{Ca}$ silicates in the mafic minerals.

\section{Homogeneity}

The grade of homogeneity of lunar glassy particles is highly variable and can be related to the presence of crystalline or glassy inclusions or, on a smaller scale, to slight concentration gradients sometimes evident near the boundary of a particle.

An approximate estimate of the range of variability in homogeneity of the analyzed glasses is shown in Table IV, where all the coefficients of variation of $\mathrm{Si}, \mathrm{Al}, \mathrm{Fe}$ and $\mathrm{Ca} \mathrm{X}$-ray intensities are given. Counting statistics are less than $2 \%$ for $\mathrm{Si}$, less than $3 \%$ for $\mathrm{Al}, 1-3 \%$ for $\mathrm{Fe}$ and $1-3 \%$ for $\mathrm{Ca}$. On these grounds, about half of the analyzed glasses are shown to be definitely inhomogeneous.

Let us consider for instance the profile given in Figure 5, referring to a traverse on a pseudo-equatorial section of an ellipsoidal glass fragment. The sharp increase in the silica content near the left edge is associated with the almost total depletion in $\mathrm{Al}_{2} \mathrm{O}_{3}, \mathrm{FeO}, \mathrm{CaO}, \mathrm{MgO}$ and is evidence of a nearly pure silica inclusion. Some other glasses, such as sphere 10 (Figure 6) show only smaller scale inhomogeneities, but 


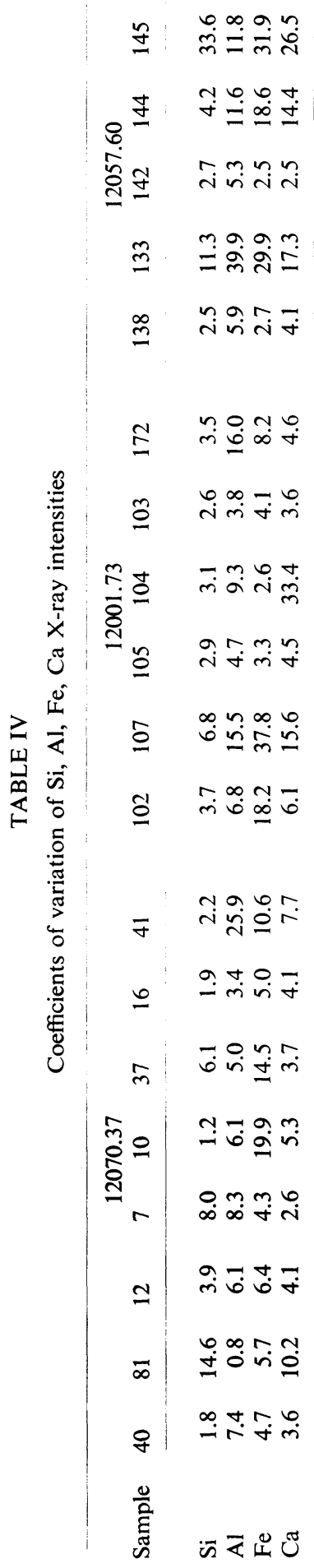




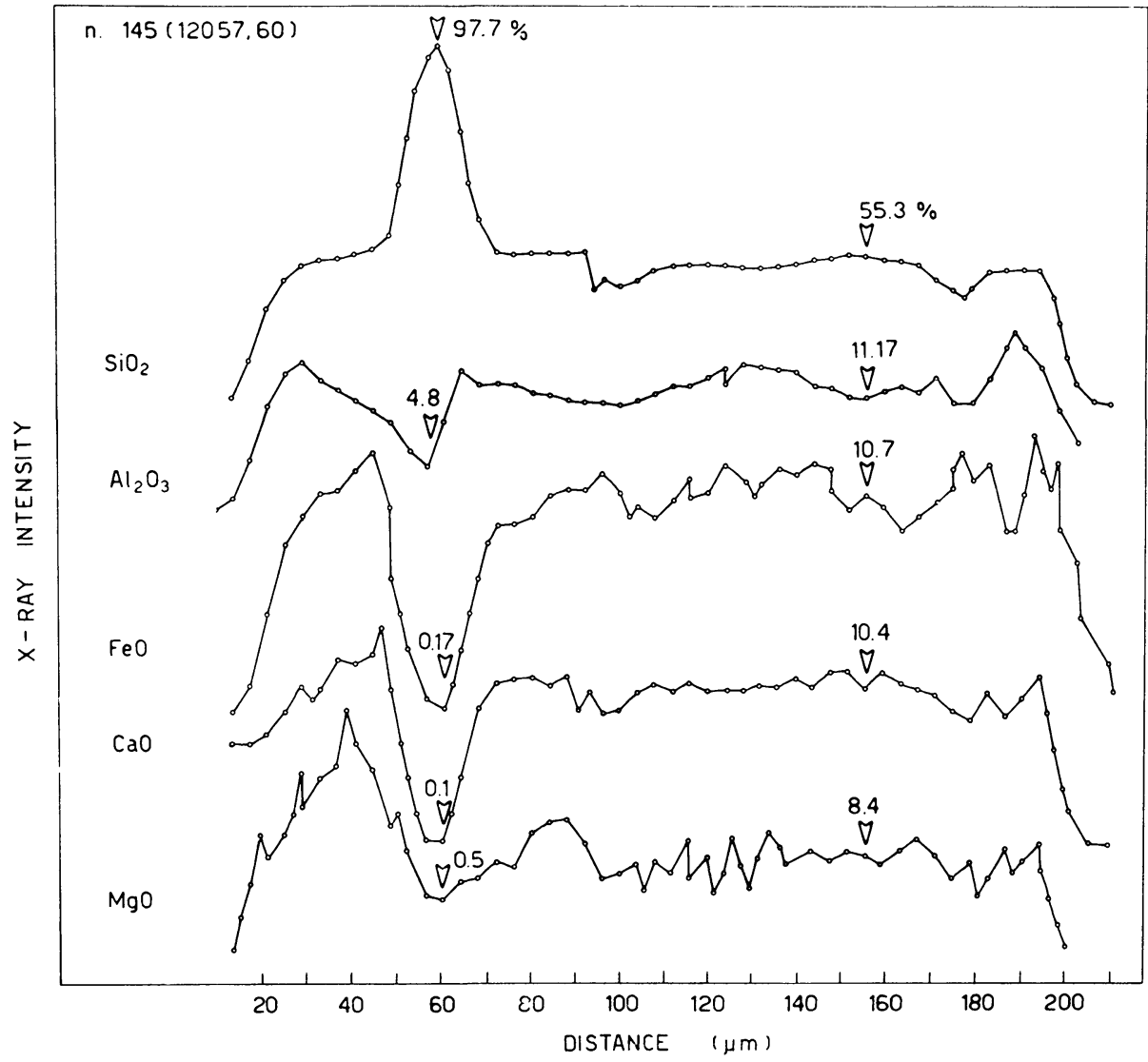

Fig. 5. Slow scan profiles of the ellipsoidic glass No. 145. The profiles are from count rates at different scales and the figures on each profile indicate concentration variations.

at the margin, the alkalies reach levels greater than the reported value for the bulk composition. Other anomalies are evident for $\mathrm{Fe}, \mathrm{Ti}$ and probably $\mathrm{Mg}$, which are also enriched at the boundary. According to Cooper et al. (1971) such inhomogeneities can represent a diffusion zone between two adjoining mineral compositions. The symmetrical enrichment at both sides of the traverse may suggest another possible explanation for alkalies involving condensation in the impact cloud.

Some of the analysed glasses show a more or less pronounced vesiculation (Figure 7). Drops and other less regular shapes are in general more vesicular than perfect spheres and this has been explained by Agrell et al. (1970) by perfect melting, degassing and homogenization for the latter, while the former have undergone nearly complete melting, partial degassing and homogenization.

Glass 172 is ovoid in shape, inhomogeneous and vesiculated. A partial traverse on a pseudo-equatorial section shows a marked inhomogeneity near the margin on the left side and a large vesicle on the right side (between 50 and $70 \mu \mathrm{m}$ in distance) 


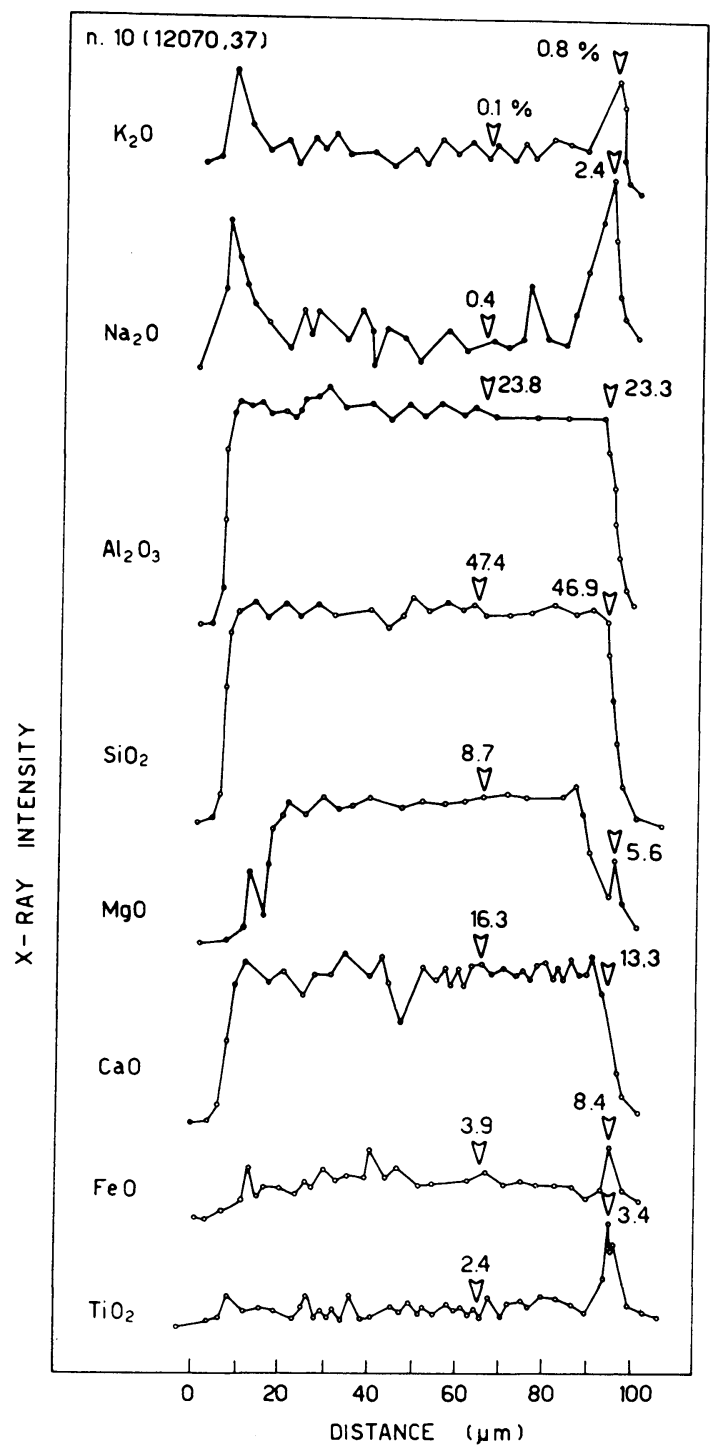

Fig. 6. Slow scan profile of the glassy sphere No. 10. The particle has a diameter of about $100 \mu \mathrm{m}$, is fairly homogeneous and free from vesiculation. The profiles are from count rates at different scales; the figures on each profile indicate concentration variations.

associated with a strong increase in the alkali content (Figure 8). A similar pattern can be seen in Figure 9. The glass consists of a sphere of gabbroic composition and appears hollow, the inside being occupied by a single vesicle. In this glass the increase in alkali along the vesicle wall appears very high: something like 25 times $\left(\mathrm{K}_{2} \mathrm{O}\right)$ and 40 times $\left(\mathrm{Na}_{2} \mathrm{O}\right)$ the recorded values over the whole section of the glassy particle. The experimental studies of Blonder et al. (1970) on heating basalts with a laser source 


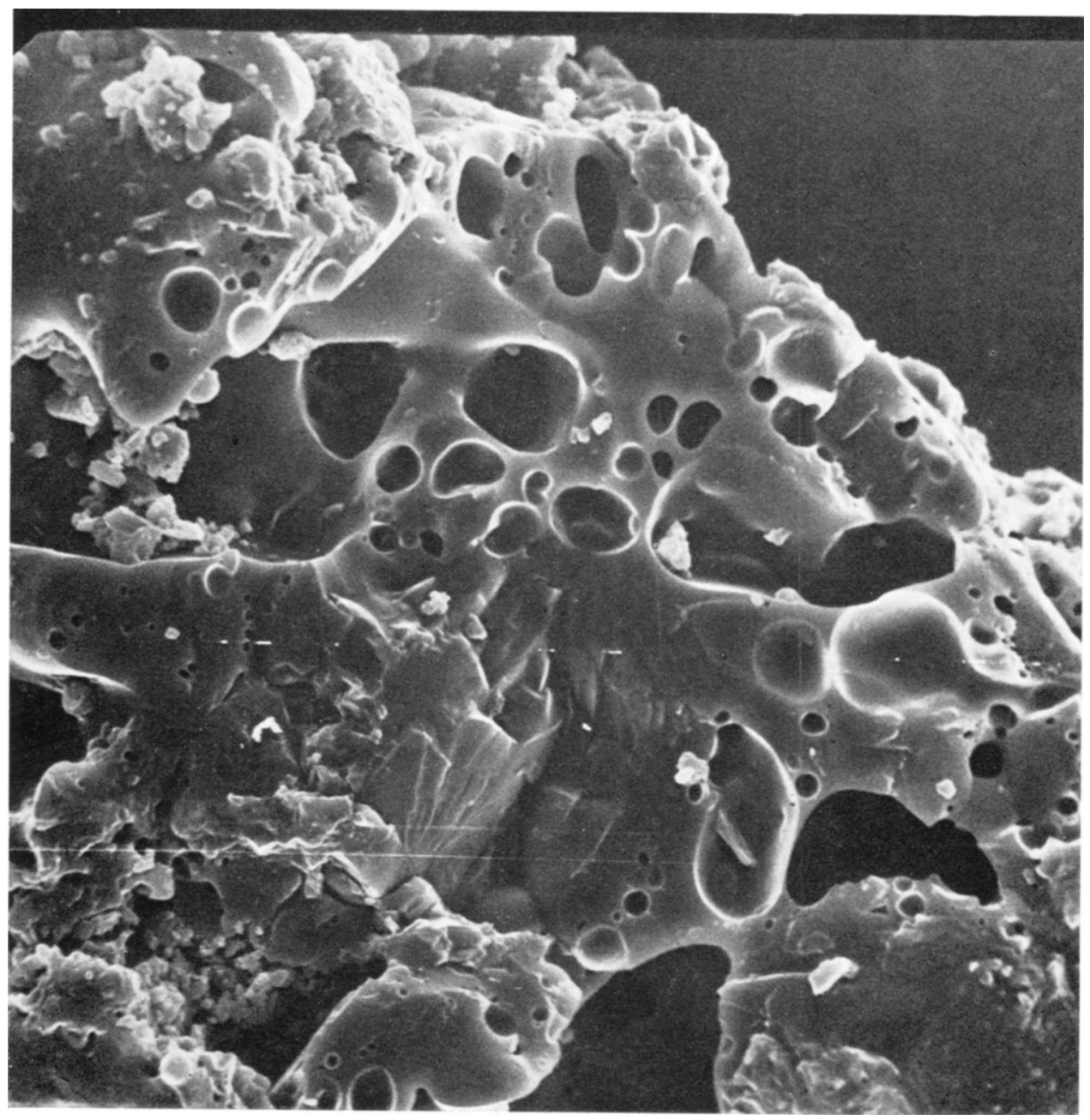

Fig. 7. SEM picture of an inhomogeneous glassy fragment also showing an extensive vesticulation. Magnification is $\times 1800$.

show there is strong alkali enrichment in the vapour phase formed by the volatilization of the material at the point of impact. Condensation of this vapour phase along the walls of vesicles could explain the observed alkali enrichment.

\section{Conclusions}

The chemistry of the glasses analysed falls within the range of types already observed by other investigators; most of the particles can be plotted in the field of gabbro composition and show a major trend towards the light compositions termed 'anorthosites' in established lunar nomenclature. The occurrence of an oversaturated composition 


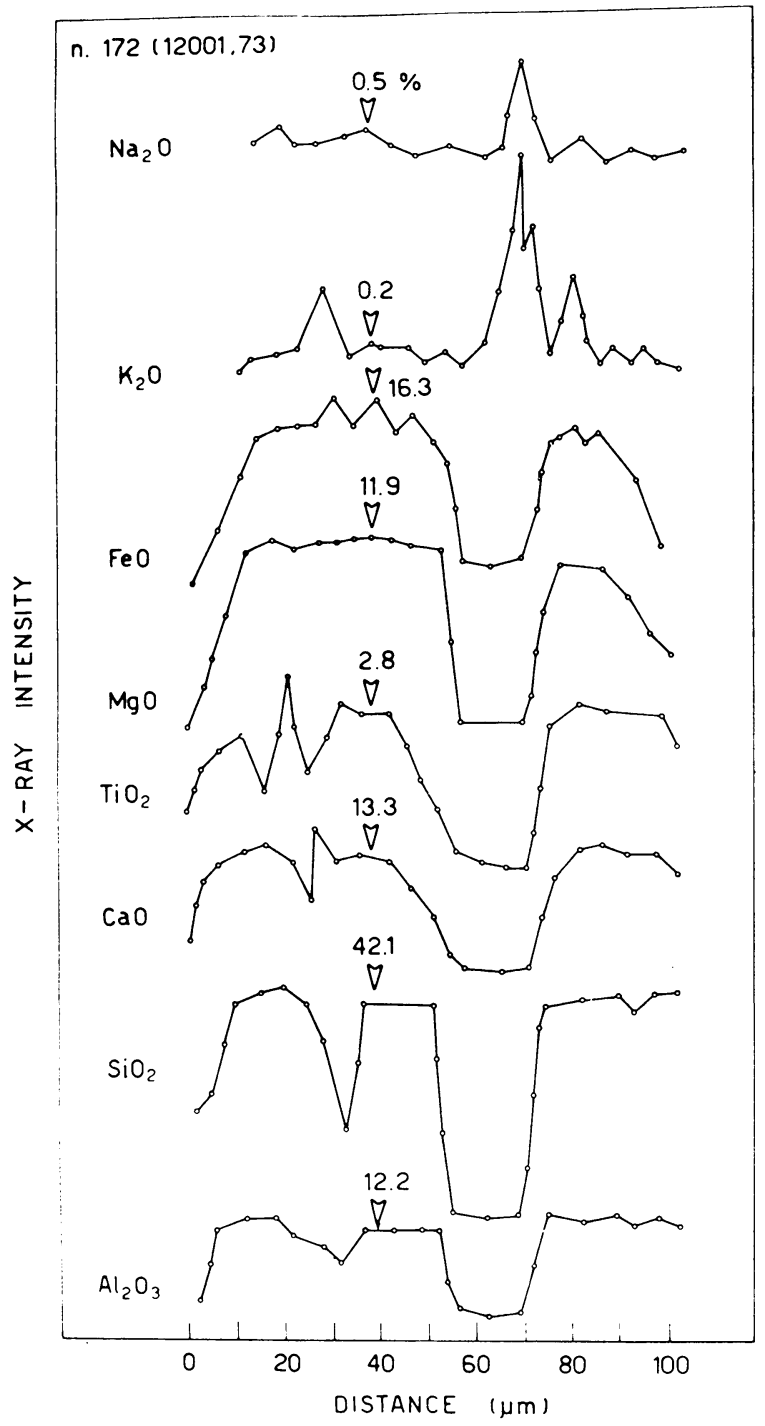

Fig. 8. Slow scan profiles of the glassy particle No. 172. The reported partial traverse has been taken from a pseudo-equatorial section of the glass $200 \mu \mathrm{m}$ in size. The profiles are from count rates at different scales and eventually are not exactly from the same line.

requires a high silica parent material or is more unlikely due to some kind of fractionation during the glass formation process.

The origins reported for most of the glassy shapes have been ascribed to the melting in various proportions of mineral phases such as pyroxene, olivine, or of other glasses as the result of the impact of meteoroids on the lunar surface.

The low alkali values often observed in the glasses analyzed and the ratios of the 


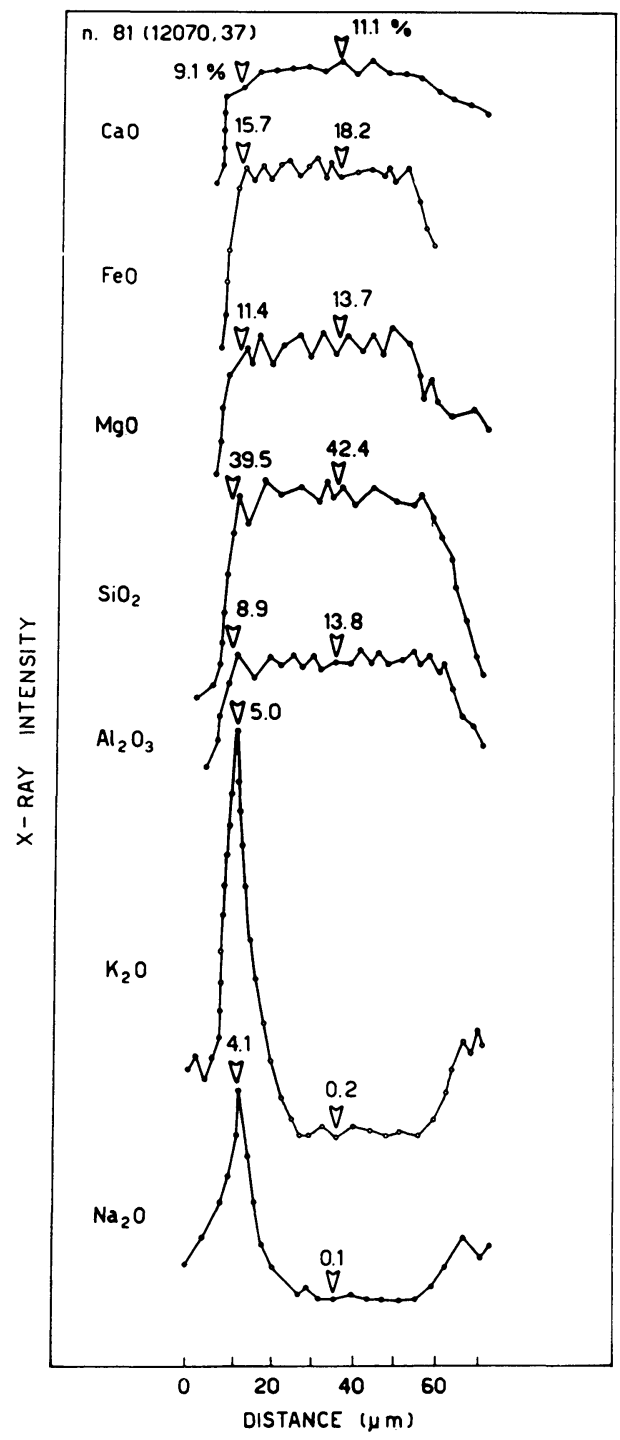

Fig. 9. Slow scan profiles of the glassy sphere No. 81. Traverse is from a pseudo-equatorial section of the particle with diameter about $160 \mu \mathrm{m}$. The inside is hollow, being occupied by a single vesicle. The profiles are from the solid part of the particle (the outside is on the right while the inside is on the left) and show the strong alkali enrichment along the boundaries of the vesicle. The figures on each profile indicate concentration variations. 
$\mathrm{Na}$ and $\mathrm{K}$ values that sometimes differ from those previously observed for rocks and lithic fragments are probably related to the peculiar behaviour of the alkalies in the impact event. On the other hand, the microprobe examinations of vesiculated glasses lead to the conclusion that if there is a strong alkali enrichment at the boundary between glass and vesicle, this can be explained as the result of condensation of these elements after volatilization in the impact cloud and of the condensed material being trapped within the vesicles by immediate cooling.

\section{Acknowledgements}

The writer wishes to express his gratitude to $\mathrm{Dr}$ and Mrs S. O. Agrell who very kindly reviewed the manuscript. Many thanks are due to Professor B. Accordi and Professor C. Lauro for making this work possible and to the colleagues of CNR research group on the lunar dust for helpful discussions. The research has been supported by a CNR grant.

\section{References}

Agrell, S. O., Long, J. V. P., and Reed, S. J. B.: 1971, 'Glasses from Apollo 11 and 12 Soils and Microbreccias', Second Lunar Science Conference (unpublished proceedings).

Blander, M., Keil, K., Nelson, L. S., and Skaggs, S. R.: 1970, Science 170, 435.

Burri, C.: 1964, Petrochemical Calculations, Sivan Press.

Carusi, A., Coradini, A., Fulchignoni, M., and Magni, M.: 1972, this volume, p. 180.

Chao, E. C. T., Boreman, J. A., Minkin, J. A., James, O. B., and Desborough, G. A.: 1970, J. Geophys. Res. 75, 7445.

Cooper, A. R., Varshneya, A. K., Swift, J., and Yen, F.: 1971, 'Properties of Lunar Glasses', Second Lunar Science Conference (unpublished proceedings).

Derby, J. V., Lewis, V. A., Hale, D., Legrone, H., and Naughton, J. J.: 1971, 'Investigation of Lunar Erosion by Volatilized Alkalis', Second Lunar Science Conference (unpublished proceedings).

Isard, J. O.: 1971, 'The Formation of Spherical Glass Particles on the Lunar Surface', Second Lunar Science Conference (unpublished proceedings).

Keil, K., Prinz, M., and Bunch, T. E.: 1971, 'Mineralogical and Petrological Aspects of Apollo 12 Rocks', Second Lunar Science Conference (unpublished proceedings).

Mason, B. and Melson, W. G.: 1970, The Lunar Rocks, Wiley-Interscience.

McKay, D. S., Greenwood, W. R., and Morrison, D. A.: 1970, Geochim. Cosmochim. Acta Suppl. I 1, 673. 